\title{
Molecular hydrogen potentiates beneficial anti-infarct effect of hypoxic postconditioning in isolated rat hearts: Novel cardioprotective intervention
}

\begin{tabular}{|r|l|}
\hline Journal: & Canadian Journal of Physiology and Pharmacology \\
\hline Manuscript ID & cjpp-2016-0693.R1 \\
\hline Manuscript Type: & Article \\
\hline Complete List of Authors: & $\begin{array}{l}\text { Zálešák, Marek; Institute for Heart Research, Slovak Academy of Sciences, } \\
\text { Department of cardiovascular physiology and pharmacology } \\
\text { Kura, Branislav; Institute for Heart Research, Slovak Academy of Sciences, } \\
\text { Bratislava, Slovakia, } \\
\text { Graban, Ján; Institute for Heart Research Slovak Academy of Science, } \\
\text { Department of Cardiovascular Physiology and Pathophysiology } \\
\text { Ledvényiová-Farkašová, Veronika; Institite for Heart Research Slovac } \\
\text { Academy of Science } \\
\text { Slezak, Jan; Institute for Heart Research, Slovak Academy of Sciences, } \\
\text { Bratislava, Slovakia,, } \\
\text { Ravingerova, Tatiana; Slovak Academy of Sciences }\end{array}$ \\
\hline Keyword: & $\begin{array}{l}\text { Ischemia-reperfusion injury, ischemic postconditioning, hypoxic } \\
\text { postconditioning, molecular hydrogen, antioxidants }\end{array}$ \\
\hline & \\
\hline
\end{tabular}

\section{SCHOLARONE \\ Manuscripts}


Molecular hydrogen potentiates beneficial anti-infarct effect of hypoxic postconditioning in isolated rat hearts: Novel cardioprotective intervention

Marek Zálešák, Branislav Kura, Ján Graban, Veronika Farkašová, Ján Slezák, Tatiana Ravingerová

Institute for Heart Research, Slovak Academy of Science, Bratislava, Slovak Republic

Short tittle: Molecular hydrogen and hypoxic postconditioning in cardioprotection

Corresponding author:

Marek Zálešák MD, PhD, Institute for Heart Research, Slovak Academy of Science, P.O.BOX 104, Dúbravská cesta 9, 840 05, Bratislava, Slovak Republic

Email: mzmzalesak@gmail.com,marek.zalesak@savba.sk 


\begin{abstract}
Generation of free radicals through incomplete reduction of oxygen during ischemia/ reperfusion is well-described. On the other hand, molecular hydrogen $\left(\mathrm{H}_{2}\right)$ reduces oxidative stress due to its ability to react with strong oxidants and easily penetrate cells by diffusion, without disturbing metabolic redox reactions. This study was designed to explore cardioprotective potential of hypoxic postconditioning (HpostC) against ischemia/reperfusion (30-min global I/120-min R) in isolated rat hearts using oxygen-free Krebs-Henseleit buffer (KHB). Furthermore, the possibility to potentiate the effect of HpostC by $\mathrm{H}_{2}$ using oxygenfree KHB saturated with $\mathrm{H}_{2}(\mathrm{H} 2+\mathrm{HpostC})$ was tested. HPostC was induced by 4 cycles of 1min perfusion with oxygen-free KHB intercepted by 1 -min perfusion with normal KHB, at the onset of reperfusion. $\mathrm{H}_{2}+\mathrm{HPostC}$ was applied in a similar manner using $\mathrm{H}_{2}$ enriched oxygen-free KHB. Cardioprotective effects were evaluated on the basis of infarct size (IS, in $\%$ of area at risk, AR) reduction, post-I/R recovery of heart function and occurrence of reperfusion arrhythmias. HPostC significantly reduced IS/AR compared to non-conditioned controls. $\mathrm{H}_{2}$ present in KHB during HPostC further decreased IS/AR compared to the effect of HPostC, attenuated severe arrhythmias, and significantly restored heart function (vs. controls). Cardioprotection by hypoxic postconditioning can be augmented by molecular hydrogen infusion.
\end{abstract}

\title{
Key words:
}

Ischemia-reperfusion injury, ischemic postconditioning, hypoxic postconditioning, molecular hydrogen, antioxidants 


\section{Introduction}

The strategies that may improve prognosis of patients after infarction or cardiosurgical interventions are intensively studied. Ischemic preconditioning (IP) induced by short-term ischemic periods has been shown to enhance heart resistance against sustained long-term ischemia/reperfusion injury (Murry et al. 1986). Clinical studies have also revealed that patients with unstable angina pectoris (UAP) had better prognosis of subsequent acute myocardial infarction (AMI) than patients without UAP (Papadopoulos et al. 2011). Therefore, UAP is considered as a clinical analogue of IP (Papadopoulos et al. 2011; Švorc et al. 2003). Morever, IP applied prior to percutaneous coronary interventions improves its outcome as well as prognosis of patients with heart transplantation (Hausenloy and Yellon 2016). However, the major limitation concerning clinical application of IP emerges from the fact that protection provided by IP is a relatively short-lived phenomenon. Hence, to reduce infarct size, IP would have to be performed just before an unpredictable AMI. Therefore, a strategy that can modify reperfusion-induced adverse events by brief reperfusionreocclusion periods after long-term ischemia, termed as ischemic postconditioning (IpostC), may have a better potential to be used in AMI management (Vinten-Johansen et al. 2005a). A beneficial effect of postconditioning has also been demonstrated on cultured cardiomyocytes exposed to long-term hypoxia, when brief episodes of reoxygenation (HpostC - hypoxic postconditioning) led to an improved cell survival following persistent reoxygenation. Morever, administration of urea as an antioxidant during a HpostC protocol even further amplified protection conferred by HpostC against generation of the strong oxidant peroxynitrite $\left(\mathrm{ONOO}^{-}\right)$and enhanced cell viability during reoxygenation (Wang et al. 2006). 
Antioxidant therapy attenuates the damaging effects of reoxygenation-induced free radical generation but may also abrogate cell signaling and redox metabolic reactions (Poljsak et al. 2013). In 2007, Ohsawa et al. found that diatomic hydrogen $\left(\mathrm{H}_{2}\right)$ acts as a therapeutic and preventive antioxidant able to reduce detrimental hydroxyl radicals $(\bullet \mathrm{OH})$ and peroxynitrite $\left(\mathrm{ONOO}^{-}\right)$production in cells and preserves metabolic processes, as well as cell signaling mediated by nitric oxide radical (NO) and superoxide anion $\left(\cdot \mathrm{O}_{2}{ }^{-}\right)$(Hong et al. 2010). $\mathrm{H}_{2}$ is the smallest gas molecule consisting of two protons and two electrons and is combustible whithin $\mathrm{H}_{2}$ concentration range of $4-75 \%$. On the other hand, it is a stable gas that can react only with $\cdot \mathrm{O}_{2}^{-}$and $\bullet \mathrm{OH}$ radicals in a water environment with low reaction rate constants (Slezák et al. 2016). Although $\mathrm{H}_{2}$ is not physiologicaly present in metabolism, it has a potential to be applied as a gas for inhalation or dissolved in a drinking water in therapeutical strategies against cardiovascular, cerebrovascular, oncological, metabolic and respiratory disorders (Dixon et al. 2013). A recommended concentration of $\mathrm{H}_{2}$ in pharmaceutical products ranges from 0.8 to $0.4 \mathrm{mmol} / \mathrm{l}$. However, it was shown that drinking of water with ten times lower concentration of $\mathrm{H}_{2}$ from 0.08 to $0.04 \mathrm{mmol} / \mathrm{l}$ was also effective in neurological and metabolic disorders (Ohta et al. 2011). $\mathrm{H}_{2}$ is extremely unique due to its capability to act at the cellular level, to enter the mitochondria and even to translocate to the nucleus (Hong et al. 2010). It has been described that $\mathrm{H}_{2}$ regulates gene expression by supressing the autooxidation of phospholipid mediators in $\mathrm{Ca}^{2+}$ mediated cell signaling (Iuchi et al. 2016). Due to this mechanism the hydrogen affects activity of MAP kinases, $\mathrm{Ca}^{2+} /$ calmodulin-dependent protein kinase (CaMK), prosurvival phosphaidylinositol-3-kinase $(\mathrm{PI} 3 \mathrm{~K}) /$ protein kinase B (PI3K/Akt) cascade, and expression of myeloperoxidase, caspase-3, 12, Bcl-2 like proteins, cytokines and tumor necrosis factor- $\alpha$. (Adameová et al. 2012; Ravingerová et al. 2003; Slezák et al. 2016). Therefore, besides its antioxidant properties, $\mathrm{H}_{2}$ 
exerts anti-apoptotic, anti-inflammatory, and cytoprotective actions and prevents pathological processes such as necrosis, apoptosis and heart failure (Dixon et al. 2013).

This study was designed to evaluate the cardioprotective potential of $\mathrm{H}_{2}$ in isolated rat hearts perfused according to Langendorff and the capability of $\mathrm{H}_{2}$ to potentiate the beneficial effect of HpostC. The heart resistance to $\mathrm{I} / \mathrm{R}$ injury was assessed based on the determination of the size of infarction, recovery of left ventricular function and occurrence of reperfusioninduced malignant ventricular arrhythmias.

\section{Material and Methods}

Animals and ethical approval

Adult male Wistar rats (250-350g body weight) fed a standard diet and tap water ad libitum were used in the experiments. Animals were anesthetised by sodium pentobarbiton in a dose of 50-60 mg/kg (i. p.) combined with heparin. All studies were performed in accordance with the Guide for the Care and Use of Laboratory Animals published by US National Institues of Health (NHI publication No 85-23, revised 1996) and approved by the Animal Health and Animal Welfare Division of the State Veterinary and Food Administration of the Slovak Republic. Rats were randomly divided into three groups, and further experiments were performed in Langendorff-perfused hearts.

\section{Perfusion technique}

After rapid excision, the hearts were placed into ice-cold physiological buffer, cannulated via the aorta and perfused in the Langendorff mode with Krebs-Henselheit buffer (KHB) gassed with $95 \% \mathrm{O}_{2}$ and $5 \% \mathrm{CO}_{2}(\mathrm{pH} 7.4)$ at the constant perfusion pressure of $73 \mathrm{mmHg}$ and $37^{\circ} \mathrm{C}$. 
KHB contained (in mmol/1): $\mathrm{NaCl} 118.0 ; \mathrm{KCl} 3.2 ; \mathrm{MgSO}_{4} ; 1.2 ; \mathrm{NaHCO}_{3} ; 25.0 ; \mathrm{KH}_{2} \mathrm{PO}_{4}$ 1.18; $\mathrm{CaCl}_{2} 2.5$; glucose $11.1 \mathrm{mmol} / 1$.

Left ventricular (LV) pressure was measured by a water-filed baloon (inflated to obtain enddiastolic pressure of 5-7 $\mathrm{mmHg}$ ) inserted into $\mathrm{LV}$ and connected to a pressure transducer (MLP physiological pressure transducer, ADInstruments, Germany). LV systolic (LVSP) and diastolic pressure (LVEDP), LV developed pressure (LVDP, systolic minus diastolic pressure), maximal rates of pressure development and fall, $+(\mathrm{dP} / \mathrm{dt})_{\max }$ and $-(\mathrm{dP} / \mathrm{dt})_{\max }$, as indexes of contraction and relaxation, respectively, heart rate (HR, derived from electrogram) and coronary flow were used to assess heart function using Power-Lab/85P Chart 7 software (ADInstruments, Germany).

\section{Treatment with hydrogen}

The hydrogen treatment of isolated hearts was performed using perfusion with KHB saturated with $\mathrm{H}_{2}$. The hydrogen was dissolved in $\mathrm{O} 2$ and $\mathrm{CO} 2$-free $\mathrm{KHB}$ ( $\mathrm{pH}$ corrected to 7.4 by $\mathrm{HCl}$ ) under high pressure (40 bar) to a supersaturated level using an apparatus developed by our department. The hydrogen-enriched $\mathrm{KHB}\left(\mathrm{H}_{2}-\mathrm{KHB}\right)$ was prepared every third day and stored at atmospheric pressure at $8^{\circ} \mathrm{C}$ in aluminium flasks with no dead volume to prevent the reaction of $\mathrm{H}_{2}$ with atmospheric $\mathrm{O}_{2} \cdot \mathrm{H}_{2}$ can be applied in hypoxic conditions only because of $\mathrm{H}_{2}$ reaction with $\mathrm{O}_{2}$. Therefore, the hypoxic postconditioning had to be designed in a setting of hydrogen administration. After administration of hydrogen to hypoxic buffer $\mathrm{pH}$ was 7.8, which then was corrected by $\mathrm{HCl}$ to 7.4 . The hydrogen-enriched $\mathrm{KHB}$ was warmed to $37^{\circ} \mathrm{C}$ and heating of solution did not change its $\mathrm{pH} . \mathrm{H}_{2}$ concentration was measured by titration using metylene blue and colloidal platinum according to Seo et al. (2012) immediately prior to using $\mathrm{H}_{2}-\mathrm{KHB}$ in heart perfusion. The concentration of hydrogen in $\mathrm{H}_{2}-\mathrm{KHB}$ was not lower than $0.3 \mathrm{mmol} / \mathrm{l}$. 


\section{Experimental protocols}

The number of animals per group was $8-10$. The isolated hearts in all groups were allowed to stabilise (20 $\mathrm{min}$ ) before further interventions. Schemes of experimental protocols are shown in Fig. 1.

1. In the control group (C), after a stabilisation period, hearts were exposed to 30-min global zero-flow ischemia followed by 120 -min restoration of perfusion (reperfusion). During the whole protocol of ischemia/reperfusion, except the ischemic period, the hearts of this group were perfused with a standard $\mathrm{KHB}$ saturated with $\mathrm{O}_{2}$ and $\mathrm{CO}_{2}$.

2. Hypoxic postconditioning (HpostC) was induced immediately after ischemia, by four cycles of 1-min perfusion with oxygen-free KHB (hypoxia) intercepted by 1-min perfusion with a standard $\mathrm{O}_{2}$ and $\mathrm{CO}_{2}$ saturated KHB. That was followed by 120 minreperfusion like in protocol 1.

3. Hydrogen treatment was applied in a setting of hypoxic postconditioning $\left(\mathrm{H}_{2}+\mathrm{HpostC}\right)$ in a similar manner like HpostC, however, $\mathrm{O}_{2}$ and $\mathrm{CO}_{2}$-free $\mathrm{KHB}$ was saturated with $\mathrm{H}_{2}$.

\section{Determination of infarct size}

The infarct size was determined according to Ravingerová et al. (2009). Briefly, after 120-min reperfusion, hearts were perfused with $1 \%$ 2,3,5 triphenyltetrazolium chloride (TTC, Sigma, USA) dissolved in $0.1 \mathrm{~mol} / 1$ phosphate buffer ( $\mathrm{pH} 7.4$ ) to stain the surviving myocardium in the whole left ventricle. Stained hearts were incubated in phosphate buffer for $30 \mathrm{~min}$ at $37^{\circ} \mathrm{C}$ than stored overnight in $10 \%$ formaldehyde. The hearts were then cut perpendicularly to the long axis of the ventricle into slices 1-2 mm thick and residues of right ventricles were removed. Both sides of slices were subsequently photographed, and non-stained infarcted area 
representing infarct size (IS) within the whole risk area (AR) in LV slices was evaluated using non-commercial planimetric software. The IS was normalised to the AR (IS/AR).

\section{Evaluation of reperfusion-induced arrhythmias}

The electrogram recording was used for the measurement of reperfusion arrhytmias, such as the total number of extrasystoles (ES), number of episodes and total duration of ventricular tachycardia (VTE and VTD, respectively), number of episodes and total duration of ventricular fibrillation (VFE and VFD, respectively). Arrhythmias severity was evaluated using an arrhytmia score calculated in accordance with the presence of the most severe form of arrhytmias in each individual heart and used for a group analysis (Curtis and Hearse 1989).

$0-$ no arrhythmias

1 - presence of extrasystoles only

2 - bigeminy/salves only

3 - ventricular tachycardia only

4 - ventricular fibrillation

5 - ventricular fibrillation, duration more than $2 \mathrm{~min}$

\section{Statistical analysis}

All data are expressed as means \pm SEM. One-way ANOVA and subsequent StudentNewman-Keuls test were used for comparing differences in normally distributed variables between the groups. Variables with nonparametric distribution (VT occurrence, VF duration) were compared using Mann-Whitney test or by using Fisher exact test for VF incidence. Differences between the groups were considered significant at $p<0.05$. 


\section{Results}

Characteristics of isolated hearts

The baseline preischemic values of heart rate, LVSP, LVEDP, LVDP, +/-(dP/dt $)_{\max }$, and coronary flow in all groups of isolated hearts prior to further interventions are summarized in Table 1. There were no significant differences in baseline hemodynamic parameters between the groups.

\section{Size of myocardial infarction}

As shown in Fig. 2, both hypoxic postconditioning and hydrogen treatment in a setting of hypoxic postconditioning significantly reduced IS/AR in comparision with infarct size in nonpostconditioned controls $(24.6 \pm 0.9 \%$ and $16.7 \pm 0.8 \%$, respectively, vs. $38.7 \pm 1.4 \%$ in controls; $p<0.05)$. Moreover, hydrogen treatment significantly decreased IS/AR compared to infarct size in postconditioned hearts that were not subjected to hydrogen treatment $(16.7 \pm$ $0.8 \%$ vs. $24.6 \pm 0.9 \%, p<0.05)$

Post-I/R parameters of LV function

The timecourse of post-I/R recovery of systolic function expressed as $\%$ of the baseline values of LVDP is shown in Fig. 3A, and the development of diastolic dysfunction manifested as changes in end-diastolic pressure (LVEDP) during reperfusion is shown in Fig. 3B. Recovery of LVDP at 40 min of reperfusion was higher than in the controls in both postconditioned groups (Fig. 3A). However, LVDP was significantly improved only in the H2-enriched postconditioned group $\left(\mathrm{H}_{2}+\mathrm{HpostC}: 62 \pm 12 \%\right.$ vs. $23 \pm 3.6 \%$ in controls; $\left.p<0.05\right)$. In addition, LVDP recovery was significantly improved in $\mathrm{H}_{2}+$ HpostC group vs. controls $(p<0.05)$ 
starting at the 5 th min of sustained reperfusion with $\mathrm{O}_{2}$-rich $\mathrm{KHB}$ (Fig. 3A). LVEDP was significantly decreased in both conditioned groups to a similar level (HpostC: $22.0 \pm 6.0$ mmHg, $\mathrm{H}_{2}+$ HpostC: $28.6 \pm 5.8 \mathrm{mmHg}$ vs. $54.7 \pm 7.2 \mathrm{mmHg}$ in controls, both $p<0.05$, Fig. $3 B)$.

HpostC also significantly improved post-I/R recovery of $-(\mathrm{dP} / \mathrm{dt})_{\max }(62 \pm 13$ vs. $28 \pm$ $2.9 ; p<0.05$ ) as the index of relaxation (Fig. 4B). Similarly, restoration of coronary flow expressed as $\%$ of preischemic values was significantly higher in the HpostC group than in the controls $(86 \pm 11 \%$ vs. $57 \pm 12 \% ; p<0.05)$ (Fig. 5). Presence of $\mathrm{H}_{2}$ significantly improved recovery of $+(\mathrm{dP} / \mathrm{dt})_{\max }$ (index of contraction, $56.4 \pm 9.3 \%$ vs. $26 \pm 2.6 \% ; p<0.05$ ) and further increased $-(\mathrm{dP} / \mathrm{dt})_{\max }$ recovery $(78 \pm 4.5 \%$ vs. $28.2 \pm 2.9 ; p<0.01)$ (Fig. $\left.4 \mathrm{~B}\right)$, as well as restored coronary flow to its preischemic values $(102 \pm 16 \%$ vs. $57 \pm 12 \%$ in the controls; $p<0.01)$ (Fig. 5).

\section{Reperfusion arrhythmias}

Differences in parameters of reperfusion-induced arrhythmias between both postconditioned groups and controls are summarized in Table 2. However, not all of them reached the levels of statistical significance. Nevertheless, the number of VT episodes in HpostC group was significantly decreased as compared with VTE in controls $(3.3 \pm 1.5$ vs. $19.8 \pm 6.9)$. Moreover, the incidence of the most severe form of arrhythmias, VF, was lower in HpostC group and further decreased in $\mathrm{H} 2+\mathrm{HpostC}$ group ( $17 \%$ vs. $58 \%$ in controls). In addition, VF duration was significantly reduced only in the $\mathrm{H}_{2}+\mathrm{HpostC}$ group as compared to that in nonconditioned controls $(p<0.05)$. Accordingly, the overall severity of arrhythmias in $\mathrm{H} 2+\mathrm{HpostC}$ group as assessed by arrhythmia score was significantly lower than in the controls $(p<0.05)$. 


\section{Discussion}

In this study, we demonstrated that hypoxic postconditioning improves heart resistance to I/R lethal injury, post-ischemic recovery of heart function and attenuates post-I/R arrhytmias, similar to ischemic pre- or postconditioning. The experimental results showed smaller infarcts (Fig. 2. A,B), and better post-I/R recovery of functional parameters - LVDP, LVEDP (Fig. 3. $A, B)$, rate of relaxation $\left[-(\mathrm{dP} / \mathrm{dt})_{\max }\right]$ (Fig 4. B) and coronary flow (Fig. 5). HpostC also decreased the number of episodes of ventricular tachycardia (Table. 2). The short-term hypoxic stress after prolonged ischemia as a therapeutic strategy has a higher potential to be used in clinical practice than IP. This is because although the acute myocardial infarction may be indeed foreseen, it always occurs unexpectedly. Morever, it seems that intervention by brief hypoxic episodes has some advantages over brief ischemia. It has been observed that IpostC-induced antiinfarct protection may be effective when the algorithm of brief R/I cycles takes from 10 to $30 \mathrm{sec}(30 \mathrm{sec}$ reperfusion $+30 \mathrm{sec}$ reischemia) whereas the 1-min algorithm is ineffective (Vinten-Johansen et al. 2005b). However, HpostC was also protective in cultured myocytes using a longer (5-min) algorithm of reoxygenation/rehypoxic cycles and improved cell survival during subsequent sustained reoxygenation (Wang et al. 2006). Similarly, a 3-min algorithm of hypoxic reperfusion effectively improved recovery of heart function and suppressed oxidative injury during oxygen restoration in a setting of Langendorff perfusion (Serviddio et al. 2005). An algorithm of a longer period of conditioning with preserved coronary flow may also allow a prolonged pharmacological cointervention with brief hypoxic cycles, e.g., using heart perfusion with cardioplegic solutions in a heart-lung apparatus. 
Both preconditioning and postconditioning have equal importance in cardioprotection. Both reduce apoptotic processes, infarct size, severity of reperfusion arrhytmias, attenuate endothelial dysfunction, inflammatory processes and improve recovery of left ventricular function. Many aspects of their mechanisms are similar, but some are different. The differences depend on the timing of their application. While preconditioning can stimulate an adaptive response in the area at risk that increases tissue resistance against long-term ischemia, the mechanisms of postconditioning do not involve this biochemical effect (Johansen-Vinten et al. 2005b). Moderate generation of oxygen free radicals during an IP protocol plays a pivotal role in cell signaling-induced cardioprotection against prolonged ischemia (Downey et al. 2007; Matejíková et al. 2009). On the other hand, postconditioning induced by brief ischemia-reperfusion or hypoxia-reoxygenation cycles reduces oxidative stress and lipid peroxidation during recovery of oxygen supply (Sun et al. 2005). Oxidative stress indirectly alters intracelular $\mathrm{Ca}^{2+}$ homeostasis due to activation of the $\mathrm{Na}^{+} / \mathrm{Ca}^{2+}$ exchanger (reverse mode) and ryanodine receptors by phosphorylation of $\mathrm{Ca}^{2+} /$ calmodulindependent protein kinase II (Adameová et al. 2012). Further mechanisms involve depression of $\mathrm{Ca}^{2+}$ uptake by sarcoplasmatic reticulum following alteration of sarco/endoplasmic $\mathrm{Ca}^{2+}$ ATPase. Disorders of $\mathrm{Ca}^{2+}$ homeostasis lead to reperfusion arrhytmias and impaired heart function (Sovari 2016). Therefore, HpostC might probably prevent $\mathrm{Ca}^{2+}$ overload observed in cardiomyocyte cultures (Sun et al. 2005) and improve recovery of functional parameters in isolated perfused hearts during prolonged reoxygenation (Serviddio et al. 2005). This antioxidant efficacy is involved in a passive PostC-mechanism based on gradual recovery of oxygen supply, which does not depend on cell signalling (Vinten-Johansen et al. 2005b). However, there are discrepances with respect to the additive effect of antioxidants coadministered with postconditioning. Thus, application of a peroxynitrite scavenger completely abrogated the IpostC-induced prosurvival effect in open-chest in vivo dog experiments (Li et 
al. 2013). However, application of the scavenger in cultured cardiocytes further improved viability of hypoxically postconditioned cells (Wang et al. 2006). Therefore, it seems that in postconditioning, both passive antioxidant efficacy and active mechanisms based on free radicals-induced cell signaling (that may be blunted by free radical scavengers) play an important role in cell survival during prolonged reperfusion (Vinten-Johansen et al. 2005a).

Diatomic hydrogen was proposed as a novel antioxidant that selectively reduces levels of toxic reactive oxygen species (ROS). It was reported that molecular $\mathrm{H}_{2}$ reduces hydroxyl radicals $(\bullet \mathrm{OH})$ and peroxynitrite $\left(\mathrm{ONOO}^{-}\right)$as products of oxidative stress. However, $\mathrm{H}_{2}$ does not affect physiologically important $\mathrm{ROS}$, such as $\mathrm{H}_{2} \mathrm{O}_{2}, \cdot \mathrm{NO}$ or $\bullet \mathrm{O}_{2}{ }^{-}$(Hong et al. 2010), and $\mathrm{ONOO}^{-}$in a small concentration as a product of their interaction (Liaudet et al. 2009). Therefore, $\mathrm{H}_{2}$ is considered as a selective antioxidant (Hong et al. 2010). Hence, $\mathrm{H}_{2}$ coadministration is not supposed to impair cell signaling induced by postconditioning. On the other hand, in our experiments, $\mathrm{H}_{2}$ co-administration even potentiated the antiinfarct effect of HpostC (Fig. 2), and enhanced postischemic recovery of LVDP to the levels of statistical significance starting at the 5 th and 10 th min of oxygen-rich reperfusion (Fig. $3 A$ ), when ROS production reaches the highest levels (Ferrari et al. 1991). At the same time period, which is considered as critical with regards to occurrence of malignant ventricular arrhythmias associated with increased ROS production (Sovari 2016), $\mathrm{H}_{2}$ treatment resulted in a significant attenuation of severity of arrhythmias (Table 2). Furthermore, in the 40th min of the oxygen-rich reperfusion, recovery of LVDP was improved to the levels of statistical significance (Fig. $3 \mathrm{~A}$ ) coupled with significantly better recovery of contraction and relaxation rates (Fig. 4A,B), while coronary flow was restored to the preischemic values (Fig. 5). These results indicate that hydrogen treatment may have a potential to enhance the effectivity of prosurvival maneuvers, such as HpostC, and as a selective antioxidant, to preserve $\mathrm{NO} \bullet$ 
production important for dilatation of coronary arteries and recovery of coronary flow. Preservation of physiological ROS production with regards to metabolism and cell signaling, is the advantage of molecular hydrogen over other antioxidants (vitamin C, tetrakis-4sulphonatophenyl-porphyrinato iron) which may blunt antiinfarct and antistunning effects of pre- or postconditioning ( $\mathrm{Li}$ et al. 2013; Tsolvas et al. 2008). Therefore, hydrogen treatment may have a potential to be applied in a clinical practice to improve prognosis of the patients in reconvalescence after infarction or larger cardiosurgical interventions using heart-lung apparatus as well as after heart transplantation.

\section{Conclusion}

Application of molecular hydrogen appears to be beneficial in a setting hypoxic postconditioning by strengthening its cardioprotective efficiency. Potential mechanisms behind this effect might be related to the antioxidative effects of HpostC and its enhancement by hydrogen treatment. However, molecular mechanisms underlying the protective effects of hydrogen treatment remain to be elucidated.

\section{Conflict of Interest}

The authors declare that there is no conflict of interest associated with this study.

\section{Acknowledgements}

The authors are thankful to Mrs. I. Formankova and Ing. D. Pancza, for their excellent technical assistance. This study was supported by grants: VEGA SR 2/0201/15, 2/0021/15, APVV-0102-11, APVV-0241-11, APVV-15-0376, APVV-15-0607, APVV-15-0119.

\section{References}


Adameova, A., Čarnická, S., Rajtík, T., Szobi, A., Nemčekova, M., Švec, P., and Ravingerová, T. 2012. Upregulation of CaMKIId during ischemia-reperfusion is associated with reperfusion-induced arrhythmias and mechanical dysfunction of the rat heart: involvement of sarcolemmal Ca2+-cycling proteins. Can. J. Physiol. Pharmacol. 90(8):11271134. Doi: 10.1139/y2012-019. PMID:22571766.

Curtis, M.J., and Hearse, D.J. 1989. Reperfusion induced arrhythmias are critically dependent upon occluded zone size. J. Mol. Cell. Cardiol. 21: 625-627. PMID:2778810

Dixon, B.J., Tang, J., and Zhang, J.H. 2013. The evolution of molecular hydrogen: a noteworthy potential therapy with clinical significance. Med. Gas Res. 16, 3: 10. Doi:10.1186/2045-9912-3-10. PMID:23680032

Downey, J.M., Davis, A.M., and Cohen, M.V. 2007. Signaling pathways in ischemic preconditioning. Heart Fail. Rev. 12: 181-188. Doi:10.1007/s10741-007-9025-2. PMID:17516169

Ferrari, D., Ceconi, C., Curello, S., Cargnini, A., Pasini, E., De Giuli, F., et al. 1991. Role of oxygen free radicals in ischemic and reperfused myocardium. Am. J. Clin. Nutr. 53(Suppl 1): 21-22. PMID:1845919

Hausenloy, D.J., and Yellon, D.M. 2016. Ischaemic conditioning and reperfusion injury. Natur. Rev. Cardiol. 13: 193-209. Doi:10.1038/nrcardio.2016.5. PMID.26843289

Hong, Y., Chen, S., and Zhang, J.M. 2010. Hydrogen as a selective antioxidant: Review of clinical and experimental studies. J. Int. Med. Res. 38: 1893-1903. PMID.21226992 
Iuchi, K., Imoto, A., Kamimura, N., Nishimaki, K., Ichimiya, H., Yokota, T., et al. 2016. Molecular hydrogen regulates gene expression by modifying the free redical chain reactiondependent generation of oxidized phospholipid mediators. Sci. Rep. 6: 18971. doi: $10.1038 /$ srep 18971 .

Li, J., Loukili, N., Rosenblatt-Velin, N., Pacher, P., Feihl, F., Waeber, B., et al. 2013. Peroxynitrite is a key mediator of the cardioprotection affored by ischemic postconditioning in vivo. PLoS One, 8: e7033. Doi:10.1371/journal.pone.007031. PMID:23875026.

Liaudet, L., Vassalli, G., and Pacher, P. 2009. Role of peroxynitrite in the redox regulation of cell signal transduction pathways. Front. Biosci. 14: 4809-4814. PMID: 19273391.

Matejiková, J., Ravingerová, T., Pancza, D., Čarnická, S., and Kolář, F. 2009. Mitochondrial KATP opening confers protection against lethal myocardial injury and ischemia-induced arrhythmias in heart via PI3K/Akt-dependent and -independent mechanisms. Physiol. Res. 87: 1055-1062, Doi: 10-1139/y09-100

Murry, C.E., Jennings, R.B., and Reimer, K.A. 1986. Preconditioning with ischemia: a delay of lethal cell injury in ischemic myocardium. Circulation, 74: 1124-1136. PMID:3769170.

Ohsawa, I., Ishikawa, M., Takahashi, K., Watanabe, M., Nishimaki, K., Yamagata, K., et al. 2007. Hydrogen acts as a therapeutic antioxidant by selectively reducing cytotoxic oxygen radicals. Nat. Med. 13: 688-694. Doi:10.1038/nm1577. PMID:17486089

Ohta, S. 2011. Recent Progress Toward Hydrogen Medicine: Potential of Molecular Hydrogen for Preventive and Therapeutical And Therapeutical Application. Curr. Pharmaceut. Des. 17: 2241-2252. 
Papadopoulos, C.E., Zioutas, D.G., Giannakoulas, G.A., Matsiras, S., Karamitsos, T.D., Karvounis, H.I., et al. 2011. Beneficial effect of ischemic preconditioning on post-infarction left ventricular remodeling and global left ventricular function. Cardiovasc. Revasc. Med. 12: 286-291. Doi:10.1016/j.carrev.2010.11.005.

Poljsak, B., Šuput, D., and Milisav, I. 2013. Achieving the balance between ROS and antioxidants: when to use the synthetic antioxidants. Oxid. Med. Cell. Longev. 2013: Article 956792. Doi: $10.1155 / 2013 / 956792$

Ravingerová, T., Adameová, A., Kelly, T., Antonopoulou, E., Pancza, D., Ondrejčáková, M., et al. 2009. Changes in PPAR gene expression and myocardial tolerance to ischemia: relevance to pleiotropic effects of statins. Can. J. Physiol. Pharmacol. 87: 1028-1036. Doi:10.1139/y09-071. PMID:20029539

Ravingerová, T., Barančík, M., and Strnisková, M. 2003. Mitogen-activated protein kinases: A new therapeutic target in cardiac pathology. Mol. Cell. Biochem. 247: 127-138. PMID: 12841640

Seo, T., Kurokawa, R., and Sato, B. 2012. A convenient method for determining the concentration of hydrogen in water: use of methylene blue with colloidal platinum. Med. Gas Res. 2: Doi: 10.1186/2045-9912-2-1

Serviddio, G., Di Venosa, N., Federici, A., D’Agostino, D., Rollo, T., Prigigallo, F., et al. 2005. Brief hypoxia before normoxic reperfusion (postconditioning) protect the heart against ischemia-reperfusion injury by preventing mitochondria peroxide production and glutathione depletion. FASEB J. 19: 354-361. Doi:10.1096/fj.04-2338com. PMID:15746178. 
Slezák, J., Kura, B., Frimmel, K., Zálešák, M., Ravingerová, T., Vinczenczová, C., et al. 2016. Preventive and therapeutic application of molecular hydrogen in situations with excessive production of free radicals. Physiol. Res. 65(Suppl. 1): 11-28. PMID:27643933.

Sovari, A.A. 2016. Cellular and molecular mechanisms of arrhythmia by oxidative stress. Cardiol. Res. Pract. 2016: ID: 9656078. Doi:10.1155/2016/9656078.

Sun, H.Y., Wang, N.P., Kerendi, F., Halkos, M., Kin, H., Guyton, R.A., et al. 2005. Hypoxic postconditioning reduces cardiomyocyte loss by inhibiting ROS generation and intracellular $\mathrm{Ca}^{2+}$ overload. Am. J. Physiol. Heart. Circ. Physiol. 288: 1900-1908. Doi:10.1152/ajpheart.01244.2003. PMID:15563525.

Švorc, P., Šefara, P., and Baročková, I. 2003. Ischemic preconditioning - laboratory curiosity or endogenous protection of myocardium before ischaemia? Cardiol. 12: 21-27

Tsolvas, K., Iliodromitis, E.K., Andreadou, I., Zoga, A., Demopoulou, M., Iliodromitis, K.E., et al. 2008. Acute administration of vitamin C abrogates protection from ischemic preconditioning in rabbits. Pharmacol. Res. 57:283-289. Doi:10.1016/j.phrs.2008.02.003. PMID:18353674.

Vinten-Johansen. J., Yellon. D.M., and Opie. L.H. 2005a. Postconditioning. A Simple, clinically applicable procedure improve revascularization in acute myocardial infarction. Circulation, 112: 2085-2088. Doi:10.1161/circulationaha.105.569798. PMID: 16203924.

Vinten-Johansen, J., Zhao, Z.Q., Zatta, A.J., Kin, H., Halkos, M.E., and Kerendi, F. $2005 b$. Postconditioing. A new link in nature's armor against myocardial ischemia-reperfusion injury. Basic. Res. Cardiol. 100: 295-310. Doi:10.1007/s00395-005-0523-x. PMID:15793629. 
Wang, H.C., Zhang, H.F., Guo, W.Y., Su, H., Zhang, K.R., Li, Q.X., et al. 2006. Hypoxic postconditioning enhances the survival and inhibits apoptosis of cardiomyocytes following reoxygenation: role of peroxynitrite formation. Apoptosis, 11: 1453-1460. Doi:10.1007/s10495-006-7786-z. PMID: 16761110.

\section{Figure captions}

Fig. 1 Experimental protocols of ischemia-reperfusion and hydrogen treatment

Fig. 2 The effect of hypoxic postconditioning and hydrogen treatment on the size of myocardial infarction in isolated rat hearts. Representative left ventricular slices stained with TTC (A) and statistical evaluation of IS/AR (B)

IS - infarct size, AR - area at risk, C - non-postconditioned controls, HpostC - hypoxic postconditioning, $\mathrm{H}_{2}+\mathrm{HpostC}$ - hypoxic postconditioning combined with hydrogen treatment, blue line on the picture - borderline between the viable and death (infarcted) unstained myocardium. Results are means $\pm \mathrm{SEM}, n=8$-10 hearts per group. ${ }^{*} p<0.05$, HpostC and $\mathrm{H}_{2}+$ HpostC vs. C, \# $p<0.05, \mathrm{H}_{2}+\mathrm{HpostC}$ vs. HpostC.

Fig. 3 The effect of hypoxic postconditioniing and hydrogen treatment on the timecourse of post-I/R recovery of left ventricular developed pressure (A) and left ventricular enddiastolic pressure (B)

LVDP - post-I/R recovery of left ventricle developed pressure in expressed as $\%$ of basal values, LVEDP - end-diastolic pressure in $\mathrm{mmHg}, \mathrm{C}$ - non-postconditioned controls, HpostC 
- hypoxic postconditioning, $\mathrm{H}_{2}+\mathrm{HpostC}$ - hypoxic postconditioning combined with hydrogen treatment, B.I. - before ischemia, E.I. - end ischemia. Results are expressed as a means \pm SEM, $n=8-10$ hearts per group. ${ }^{*} p<0.05, \mathrm{H}_{2}+$ HpostC vs. $\mathrm{C},+p<0.05$, HpostC and $\mathrm{H}_{2}+\mathrm{HpostC}$ vs. C.

Fig. 4 The effect of hypoxic postconditioniing and hydrogen treatment on the post-I/R recovery of $+(\mathrm{dP} / \mathrm{dt})_{\max }(\mathrm{A})$ and $-(\mathrm{dP} / \mathrm{dt})_{\max }(\mathrm{B})$

$+(\mathrm{dP} / \mathrm{dt})_{\max }$ and $-(\mathrm{dP} / \mathrm{dt})_{\max }-$ maximal rates of pressure developments and fall as indexes of contraction and relaxation, respectively, $\mathrm{C}$ - non-postconditioned controls, HpostC - hypoxic postconditioning, $\mathrm{H}_{2}+\mathrm{HpostC}-$ hypoxic postconditioning combined with hydrogen treatment. Results are expressed as a means $\pm \mathrm{SEM}, n=8-10$ hearts per group. ${ }^{*} p<0.05$, HpostC vs. C, $* * p<0.01, \mathrm{H} 2+\mathrm{HpostC}$ vs. C

Fig. 5 The effect of hypoxic postconditioniing and hydrogen treatment on the post-I/R recovery of coronary flow

$\mathrm{CF}$ - coronary flow, C - non-postconditioned controls, HpostC - hypoxic postconditioning, $\mathrm{H}_{2}+$ HpostC - hypoxic postconditioning combined with hydrogen treatment. Results are expressed as a means $\pm \mathrm{SEM}, n=8-10$ hearts per group. ${ }^{*} p<0.05, \mathrm{HpostC}$ vs. C, ${ }^{* *} p<0.01$, $\mathrm{H} 2+\mathrm{HpostC}$ vs. C 
Table 1. Baseline preischemic values of hemodynamic parameters of isolated rat hearts.

\begin{tabular}{llllllll}
\hline Group & $\begin{array}{l}\text { HR } \\
(\text { beats/min) }\end{array}$ & $\begin{array}{l}\text { LVSP } \\
(\mathbf{m m H g})\end{array}$ & $\begin{array}{l}\text { LVEDP } \\
(\mathbf{m m H g})\end{array}$ & $\begin{array}{l}\text { LVDP } \\
(\mathbf{m m H g})\end{array}$ & $\begin{array}{l}+(\mathbf{d P} / \mathbf{d t})_{\max } \\
(\mathbf{m m H g} / \mathbf{s})\end{array}$ & $\begin{array}{l}-(\mathbf{d P} / \mathbf{d t})_{\max } \\
(\mathbf{m m H g} / \mathbf{s})\end{array}$ & $\begin{array}{l}\mathbf{C F} \\
(\mathbf{m l} / \mathbf{m i n})\end{array}$ \\
\hline Controls & $254 \pm 16$ & $61.3 \pm 2.8$ & $8.3 \pm 0.7$ & $53.1 \pm 2.8$ & $1864 \pm 104$ & $1085 \pm 89$ & $13.0 \pm 0.9$ \\
HPostC & $247 \pm 14$ & $65.0 \pm 3.8$ & $7.0 \pm 1.1$ & $58.1 \pm 3.2$ & $1965 \pm 111$ & $1143 \pm 147$ & $13.8 \pm 3.2$ \\
H2+PostC & $257 \pm 19$ & $60.1 \pm 2.8$ & $8.4 \pm 0.7$ & $52.1 \pm 2.9$ & $1719 \pm 60$ & $941 \pm 68$ & $13.7 \pm 1.4$ \\
& & & & & & & \\
\hline
\end{tabular}

$\mathrm{C}$ - non-postconditioned controls, HpostC - Hypoxic postconditioning, $\mathrm{H}_{2}+\mathrm{HpostC}-$ hypoxic postconditioning combined with hydrogen treatment. HR - heart rate, LVSP - left ventricular systolic pressure, LVEDP - left ventricular end-diastolic pressure, LVDP - left ventricular developed pressure (LV systolic minus LV diastolic pressure), $+(\mathrm{dP} / \mathrm{dt})_{\max },-(\mathrm{dP} / \mathrm{dt})_{\max }-$ maximal rates of pressure development and fall, respectively, CF - coronary flow. Data are means \pm S.E.M., $n=8$-10 per group. 
Table 2. Effects of hypoxic postconditioning and treatment with hydrogen on reperfusion-induced ventricular arrhythmias.

\begin{tabular}{|c|c|c|c|c|}
\hline Group & VTE & VFD (s) & VFI (\%) & AS \\
\hline Controls & $19.8 \pm 6.9$ & $14.4 \pm 9.7$ & 58 & $3.6 \pm 0.2$ \\
\hline HpostC & $3.3 \pm 1.5^{*}$ & $2.8 \pm 2.8$ & 25 & $3.2 \pm 0.2$ \\
\hline $\mathrm{H}_{2}+\mathrm{HpostC}$ & $12.0 \pm 2.9$ & $1.3 \pm 1.3^{\#}$ & 17 & $3.1 \pm 0.1^{\#}$ \\
\hline \multirow{2}{*}{\multicolumn{5}{|c|}{$\begin{array}{l}\mathrm{C} \text { - non-postconditioned controls, HpostC - hypoxic postconditioning, } \mathrm{H}_{2}+\mathrm{HpostC}-\text { hypoxic } \\
\text { postconditioning combined with hydrogen treatment, VTE - number of episodes of } \\
\text { ventricular tachycardia, VFD - duration of ventricular fibrillation, VFI - incidence of }\end{array}$}} \\
\hline & & & & \\
\hline \multicolumn{5}{|c|}{ ventricular fibrillation, AS - arrhythmic score. Results are expressed as means \pm S.E.M.; VFI } \\
\hline \multicolumn{5}{|c|}{ - in percentage of total number of hearts in group; $n=8-10$ hearts per group. ${ }^{*}$, \# $-p<0.05$} \\
\hline
\end{tabular}


Figure 1.

C

\begin{tabular}{|l|l|l|}
\hline 20 & 30 & 120 \\
\hline
\end{tabular}

HpostC

\begin{tabular}{|l|l|}
\hline 20 & 30 \\
\hline
\end{tabular}
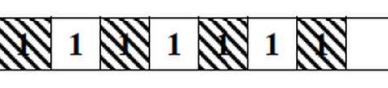

120

$\mathrm{H}_{2}+\mathrm{HpostC}$

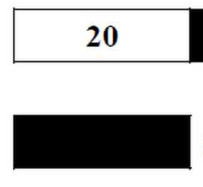

\section{0}

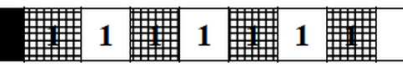

120

Zero-flow ischemia

Perfusion with standard KHB (min)

SIMाMा Perfusion with O2/CO2-free KHB (min)

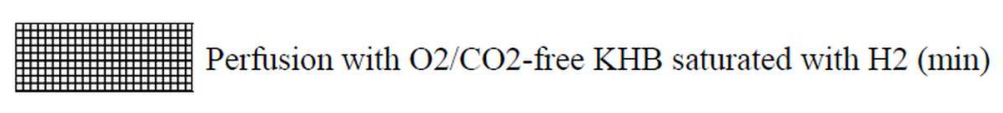

$354 \times 237 \mathrm{~mm}(300 \times 300 \mathrm{DPI})$

https://mc06.manuscriptcentral.com/cjpp-pubs 
Figure 2.

A.
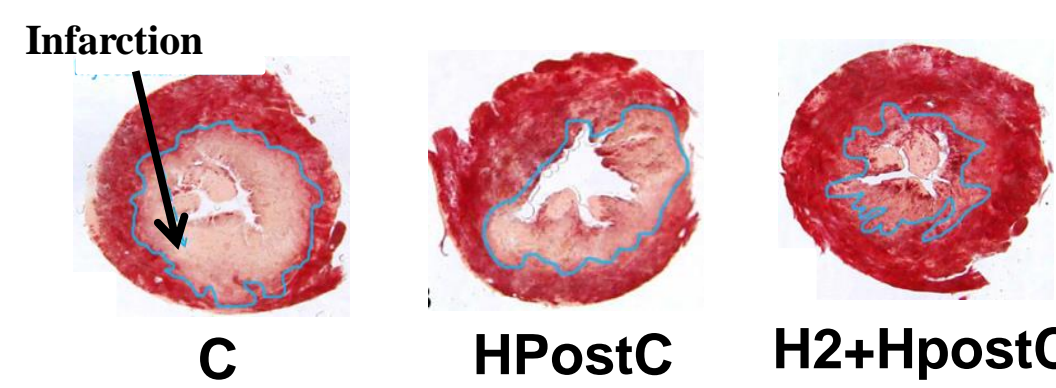

H2+HpostC

B.

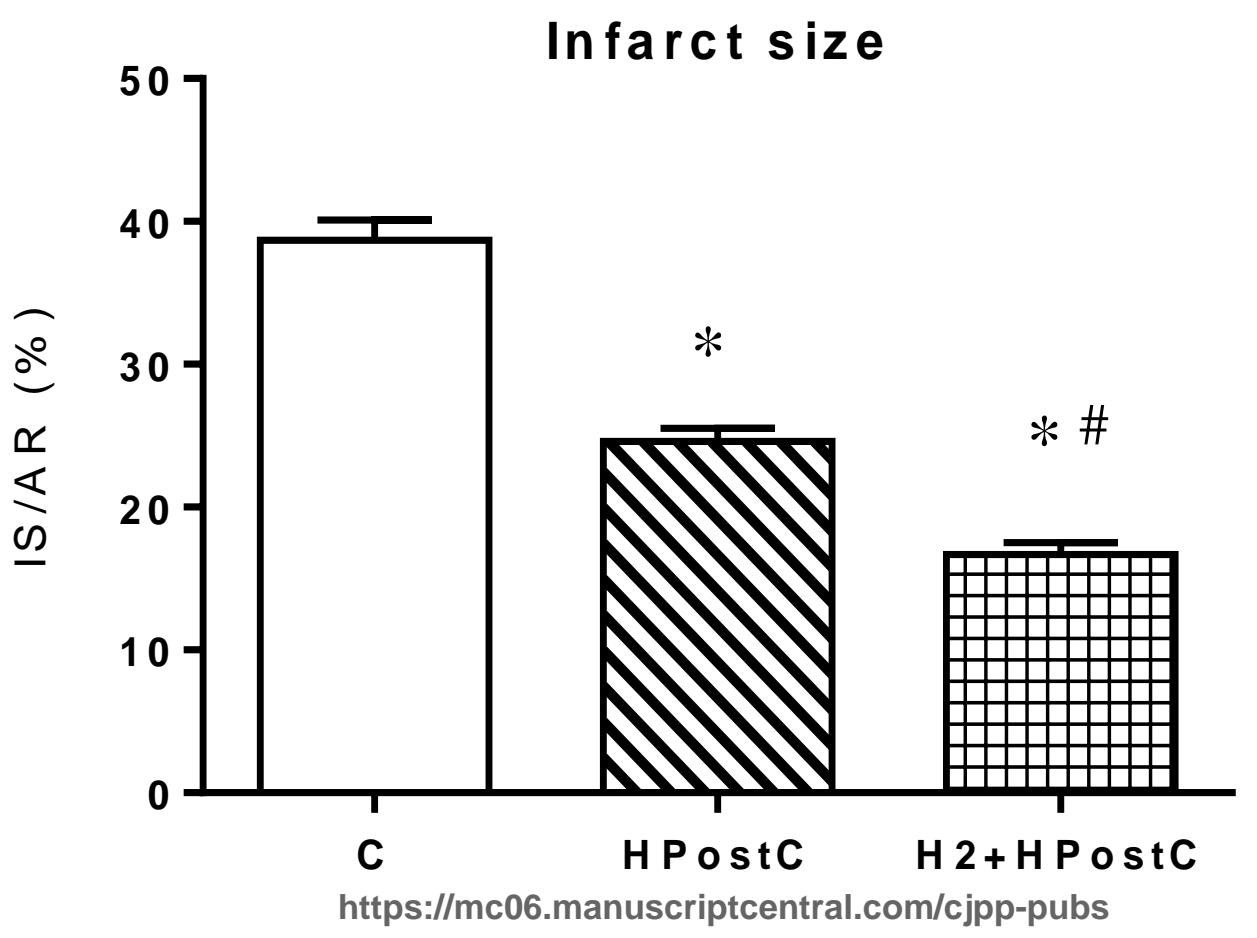




\section{Figure 3.}

A.

LVDP recovery

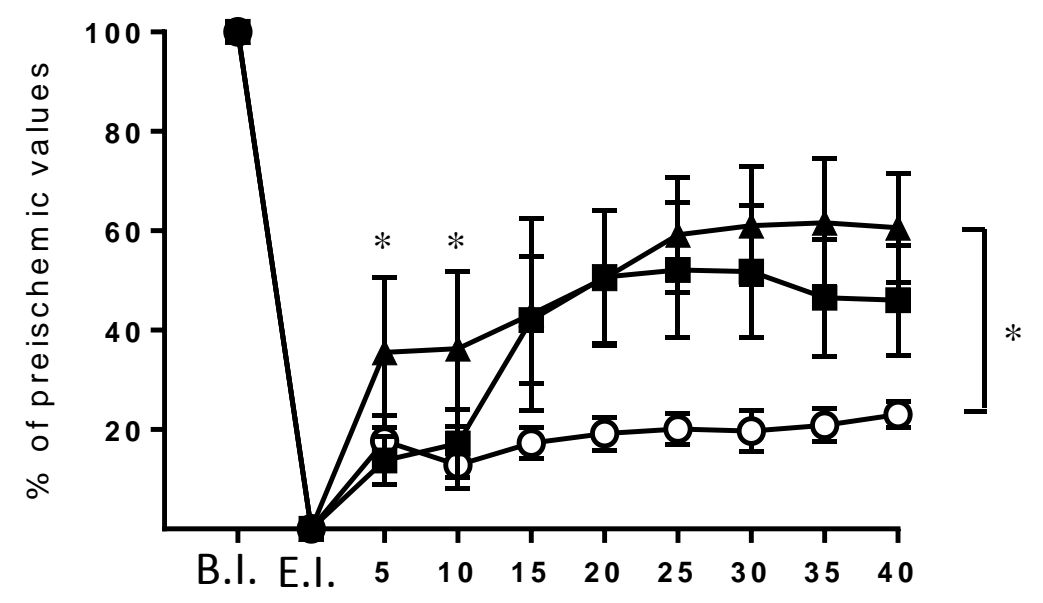

Time of reperfusion ( $m$ in)
B.

LVEDP recovery

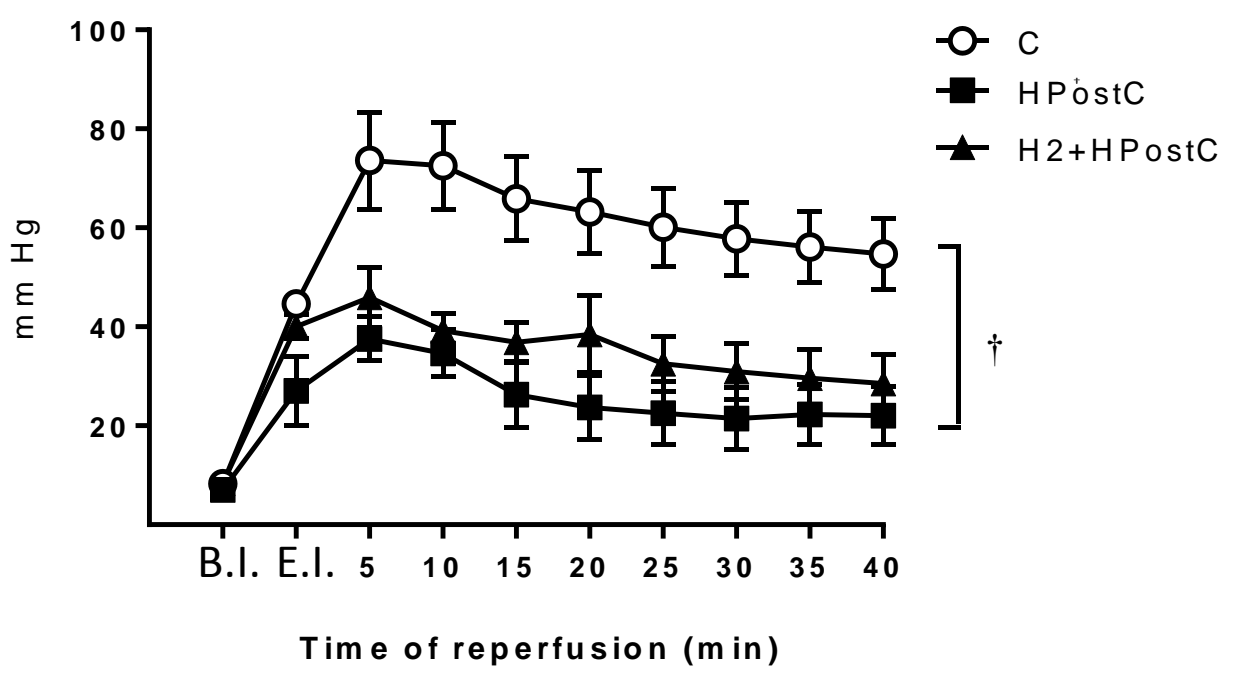


Figure 4.

A.

Recovery of $+(\mathrm{dP} / \mathrm{dt})_{\max }$

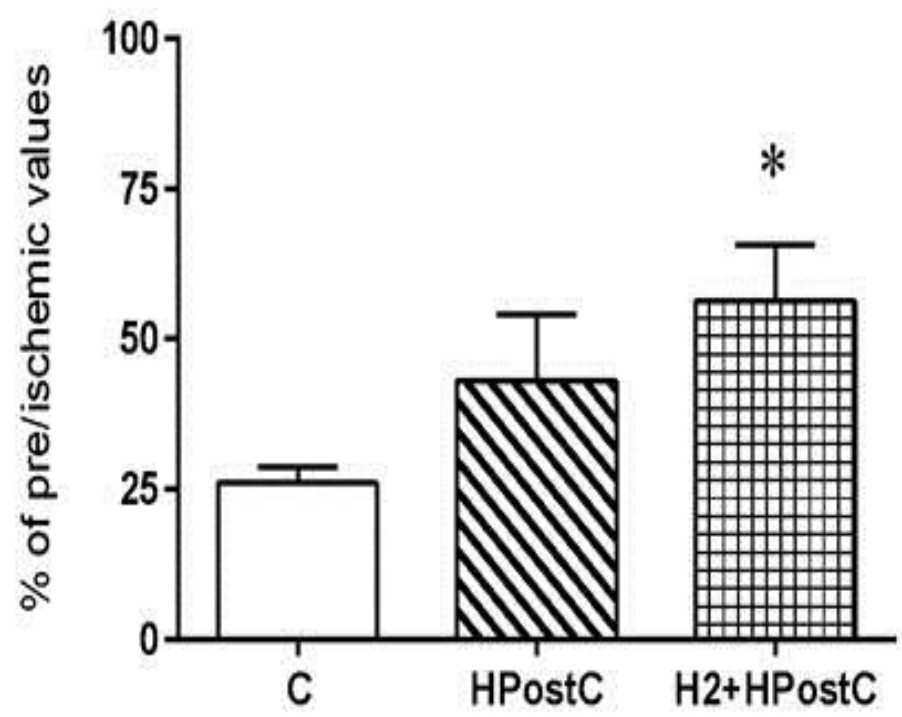

B.

Recovery of -(dP/dt) max

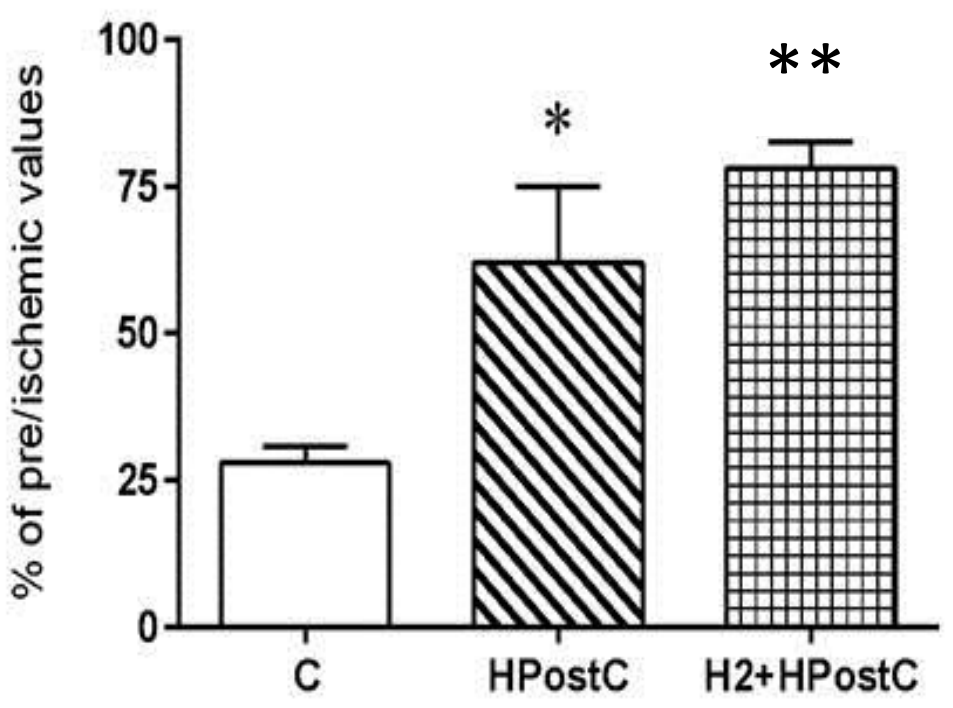




\section{Recovery of CF}

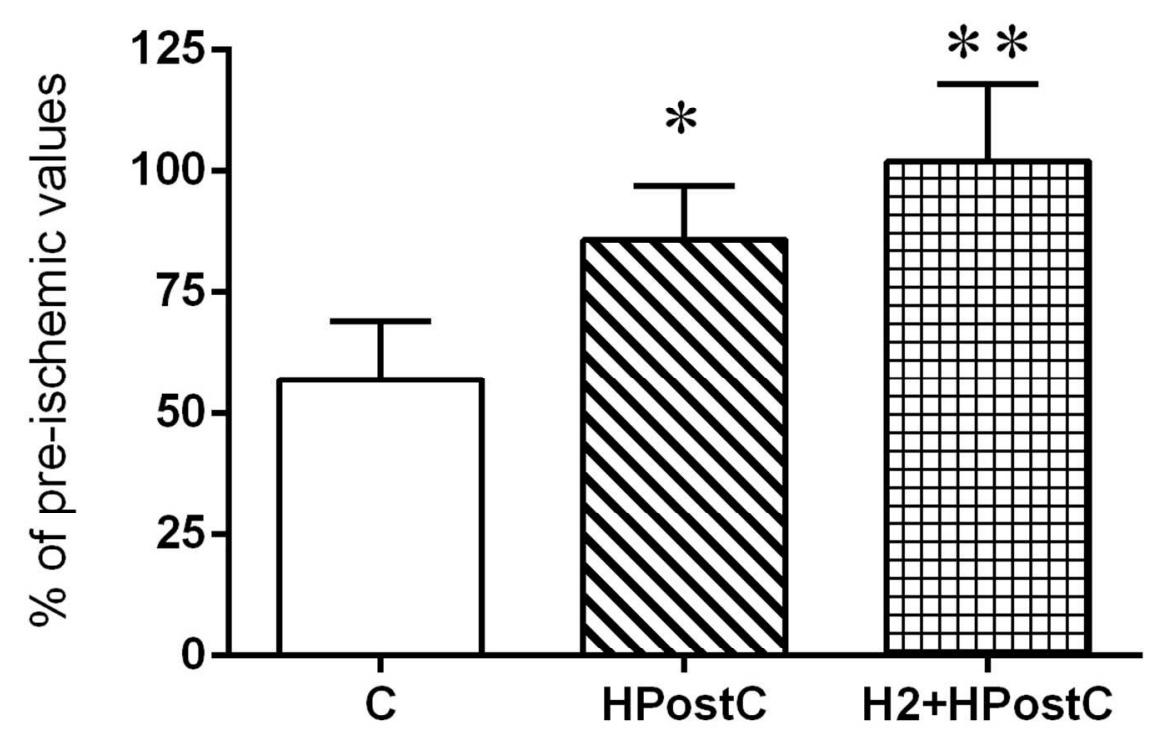

$108 \times 78 m m(300 \times 300$ DPI $)$ 